5 , T12-L1) in $2(6.2 \%)$ of 5 patients and only $1(3.1 \%)$ of them had typical CT findings including widening, irregularity and sclerosis at the L4-5 intervertebral space.

Conclusion Spondylodiscitis may have variable clinical or radiological manifestations and imaging techniques are needed to identify this uncommon complication in patients with AS.

\section{SAT0046 EVALUATION OF FUNCTIONAL STATUS AND QUALITY OF LIFE IN PATIENTS WITH ANKYLOSING SPONDYLITIS}

${ }^{1} \mathrm{EE}$ Bostan, ${ }^{1} \mathrm{P}$ Borman, ${ }^{1} \mathrm{H}$ Bodur, ${ }^{2} \mathrm{~N}$ Barca. ${ }^{1}$ Department of Physical Medicine and Rehabilitation; ${ }^{2}$ Radiology, Numune Education and Research Hospital, Ankara, Turkey

10.1136/annrheumdis-2001.398

\section{Background}

Objectives The aim of this study was to evaluate the functional status and quality of life and to determine the relationship between disability and clinical variables in a group of patients with ankylosing spondylitis (AS).

Methods Fifty-one patients with a mean age of 37.2 years were included to the study. Clinical variables including pain by visual analogue scale (VAS), functional indices by Bath ankylosing spondylitis functional index (BASFI), Dutch functional index (DFI) and Dougdas functional index (FI), metrology by Bath ankylosing spondylitis metrology index (BASMI) and disease activity by Bath ankylosing spondylitis disease activity index (BASDAI) were studied. Radiographs of the patients were scored by Bath ankylosing spondylitis radiological index (BASRI) and quality of life was assessed by Nottingham health profile (NHP). Erythrocyte sedimentation rate (ESR) and C-reactive protein (CRP) levels were also recorded.

Results The scores of BASMI and BASRI were correlated with disease duration and BASDAI scores. Functional loss assessed by BASFI, DFI and FI were strongly correlated with BASDAI, BASRI and BASMI. Patients with peripheral joint involvement had greater disability. Functional loss was more correlated with the levels of CRP than ESR. NHP scores best correlated with functional indexes followed by BASDAI.

Conclusion In conclusion, functional loss should be considered in evaluation of AS patients. These functional indexes can help to assess the patients more objectively and monitorize the treatment in order to increase the quality of life in patients suffering from this chronic condition.

\section{Osteoarthritis - Clinical aspects and treatment}

\section{AB0137 OSTEOARTHRITIS AMONG GERMAN AND EGYPTIAN PATIENTS}

AF El Ghobarey, G Bach, S Mousa, W Kamel. Internal Medicine, Al Azhar University, Cairo, Egypt

10.1136/annrheumdis-2001.399

\section{Background}

Objectives The aim of the thesis was to study the different clinical features of OA in different ethnic groups of patients.

Methods One hundred and sixty six Germans and 50 Egyptian patients with OA were studied. Clinical examination, severity index and radiological score (of all body joints) beside a battery of routine blood tests were done for each patient.

Results There was an increase in the number of joints affected and in total joint lesions among Germans. There was also an increase in age at onset, in disease duration and in family history of OA among Germans. None of the Egyptians had hip affection, while 127 Germans had bilateral or unilateral hip joint affection. Severity index of hips correlated with patients age ( $p$ $<0.05)$ and age at onset $(\mathrm{p}<0.05)$ among Germans. While, severity index of knee joint correlated with age $(\mathrm{p}<0.05, \mathrm{p}<$ $0.05)$ and age at onset ( $\mathrm{p}<0.05, \mathrm{P}-\mathrm{c} 0.05)$ among both Egyptians and Germans. While 19 Germans had DISH and 19 Germans had CPPD, none of the Egyptians had neither DISH syndrome nor CPPD. Thirteen Germans but none of the Egyptians had knee effusion.

Environmental, habitual and occupational causes, among others, seem to modify the clinical features of OA between ethnic groups of patients.

Conclusion

\section{AB0138 COMPARISON OF THREE OA TREATMENT REGIMENTS IN A TYPICAL POPULATION}

ES Tsvetkova. Osteoarthritis, Institute of Rheumatology of RAMS, Moscow, Russia

10.1136/annrheumdis-2001.400

Background A series of double-blind placebo and active comparator controlled studies meloxicam, a COX-2 inhibitor, has been found to be safe and effective in the treatment of osteoarthritis (OA) at dose of $7.5 \mathrm{mg}$ daily. To assess the efficacy and the safety of meloxicam ?standard? and $15 \mathrm{mg}$ daily doses a comparison of three OA treatment regiments in a typical population was performed.

Objectives

Methods In the open multicenter parallel-group study 630 pts with confirmed knee $\mathrm{OA}$ and a flare were treated with oral administration of meloxicam tablets [at regimens of $7.5 \mathrm{mg}(1 \mathrm{st}$ group) or $15 \mathrm{mg}$ (2nd group) daily or increasing ineffective 7.5 $\mathrm{mg} / \mathrm{d}$ to $15 \mathrm{mg} / \mathrm{d}$ after 1 week (3d group)]. Treatment was for 4 weeks, with regular assessment for drug safety and efficacy by evaluation of adverse events (AE), vital signs, Likert scales for pain at rest, at on movement, synovitis and joint function, and the patient's and investigator's overall assessment of disease activity.

Results The demographic, disease characteristics and gastrointestinal AE risk factors were similar across the treatment groups. Prior NSAID inefficacy was found in $25.5 \%$ pts. NSAID adverse events dropout have been estimated in $12.4 \%$ pts in past history. Anti-inflammatory and analgesics meloxicam properties were confirmed in three treatment regiments $(p<0.001)$. The incidence of all AE was lower and without dropout at $15 \mathrm{mg} / \mathrm{d}$ of meloxicam $(3.8 \%)$ than for $7.5 \mathrm{mg} / \mathrm{d}$ of drug $(7.8 \%$ with $3.6 \%$ dropout). The incidence of non-serious gastrointestinal $\mathrm{AE}$ was $1.6 \%$ and $3.4 \%$ (with $1.2 \%$ dropout) correspondingly. The total $\mathrm{AE}$ frequency among $630 \mathrm{OA}$ pts was $6.5 \%$ (with $2.5 \%$ dropout).

Conclusion Meloxicam is a safe and effective medication for knee OA treatment, without dose-depended incidence of AE and dropout rates. 